\section{Mild SARS in elderly patients}

T $\mathrm{n}$ their report of a nosocomial out1 break of SARS, Monali Varia and associates $^{1}$ describe 8 patients with SARS who had possible hospital exposure to unidentified individuals with the disease. This highlights the importance of diagnosing SARS, including mild cases, before it can spread to others.

A 78-year-old woman with paroxysmal atrial fibrillation, hypertension and diabetes mellitus was admitted to our hospital in April 2003 for symptomatic bradycardia. While she was under observation, an outbreak of SARS occurred in her ward. Nine days later, she exhibited fever $\left(38.2^{\circ} \mathrm{C}\right)$ but no respiratory symptoms. Mild air-space consolidation of the right lower lobe was apparent on chest radiography. She had lymphopenia $\left(0.3 \times 10^{9} / \mathrm{L}\right)$, but her platelet count and serum levels of lactate dehydrogenase and creatine kinase were normal. Three sets of samples of nasopharyngeal aspirate, stool and urine tested negative for SARS coronavirus by reverse-transcriptase polymerase chain reaction (RT-PCR) and virus isolation. Her fever subsided with empiric cefoperazone/sulbactam therapy, and she remained well. After discharge, we received the laboratory report for her day 15 titre for SARS coronavirus, which was significantly elevated (640).

This case illustrates the difficulty of diagnosing mild SARS. This patient did not fulfill the WHO criteria for SARS, ${ }^{2}$ which have a low sensitivity $(26 \%){ }^{3}$ RT-PCR and virus isolation were not sensitive enough to detect the infection, and the disease was diagnosed only with seroconversion in the convalescent phase. Better diagnostic tests are need- ed in the early phases of the disease $\mathrm{e}^{4}$ to prevent the spread of SARS to other hospital patients.

\section{Hing Ming Cheng \\ Timothy Kwok}

Department of Medicine and Geriatrics

Tai Po Hospital

Hong Kong, China

\section{References}

1. Varia M, Wilson S, Sarwal S, McGeer A, Gournis E, Galanis E, et al. Investigation of a nosocomial outbreak of severe acute respiratory syndrome (SARS) in Toronto, Canada. CMAf 2003;169(4):285-92.

2. Case definitions for surveillance of severe acute respiratory syndrome (SARS). Geneva: World Health Organization; revised 2003 May 1. Available: www.who.int/csr/sars/casedefinition/en/ (accessed 2003 Sep 17)

3. Rainer TH, Cameron PA, Smit DV, Ong KL, Hung ANW, Chan DPN, et al. Evaluation of WHO criteria for identifying patients with severe acute respiratory syndrome out of hospital: perspective observational study. BM7 2003;326: 1354-8.

4. Poon LL, Chan KH, Wong OK, Yam WC, Yuen KY, Guan Y, et al. Early diagnosis of SARS coronavirus infection by real time RTPCR. 7 Clin Virol 2003;28(3):233-8.

Competing interests: None declared.

DOI:10.1053/cmaj.1031734

\section{Small medical journals and the 10/90 problem: Educatione ad excellentiam}

\} \text { e read with great interest your } $\checkmark$ editorial on Western medical journals and the $10 / 90$ problem. ${ }^{1}$ Working in a relatively less developed environment and editing a small medical journal, we fully agree that "journals are not merely publications but sites of action." In line with your call to conceive of biomedical education as an "international enterprise," we would like to emphasize the role of journal editors in developing coun- tries. We believe that they can and should be educators within their scientific communities. ${ }^{2,3}$

In our 10 years of working with authors from a region that has experienced a devastating war and the economic crisis of post-communist market transition, ${ }^{4}$ we have learned that it is possible to build bridges between the scientific periphery and mainstream science. During the war in Croatia, we saw that our colleagues had important knowledge to share with the global medical community but lacked the skills to present that knowledge. ${ }^{5}$ We therefore introduced an authorfriendly policy to assist them to publish good articles in our journal, as well as in international medical journals., ${ }^{4,5}$ Our educational activities with authors grew into a structured teaching program involving most members of the journal's office: a mandatory course on research and writing for medical students, continuing education courses on evidence-based medicine for physicians, research electives for medical students ending in peer-reviewed publication in our Student Croatian Medical Fournal and an international workshop on scientific writing for authors in southeast Europe. We believe that our activities have contributed substantially to the development of a critical mass of researchers in our region who will be able to join the mainstream research community.

Perhaps the most effective way for Western medical journals to overcome the $10 / 90$ problem is to join hands with local journals and their editors to build research and publishing capacity in small and underdeveloped scientific communities. ${ }^{3}$ The smaller journals would publish better articles and thus increase their visibility, and the bigger journals would be better able to cover

\author{
Abbott \\ Biaxin XL \\ 4 clr. Banner \\ Repeat of Mar. 2 issue
}


global issues and open avenues for high-quality submissions.

\section{Ana Marusic \\ Matko Marusic \\ Editors in Chief \\ Croatian Medical fournal \\ Zagreb, Croatia}

\section{References}

1. Western medical journals and the $10 / 90$ problem [editorial]. CMA7 2004;170(1):5.

2. Marusic A, Marusic M. Small scientific journals from small countries: breaking from a vicious circle of inadequacy [editorial]. Croat Med 7 1999; 40(4):508-14.

3. Marusic M, Marusic A. Good editorial practice editors as educators [editorial]. Croat Med 7 2001;42(2):113-20.

4. Marusic A, Misak A, Kljakovic-Gaspic M, Marusic M. Educatione ad excelentiam - ten years of the Croatian Medical fournal. Croat Med 7 2002;43(1):1-7.

5. Marusic A, Marusic M. What can medical journal editors do in war? Lancet 2002;360(Suppl):s59-60.

6. Marusic A, Marusic M. Teaching students how to read and write science: a mandatory course on scientific research and communication in medicine. Acad Med 2003;78(12):1235-9.

DOI:10.1053/cmaj.1040034

\section{Grading evidence}

ing Group ${ }^{1}$ have taken an important first step in developing a universally acceptable grading system for denoting the quality of evidence and associated recommendations. Current systems use alphabetic, numeric or colour-coded nominals or ordinals, which represent discontinuous, qualitative (or at most semiquantitative) and hence imprecise categories. ${ }^{2,3}$ In many instances the resulting imprecision exceeds that of the information it attempts to convey. I would like to suggest an alternative.

The most informative and sophisticated form of measurement uses a continuous scale with consistent intervals. ${ }^{2}$ Interval scales are common in clinical medicine, being used for measurements of blood pressure, temperature, heart rate and weight, and for nearly all laboratory measurements. The consistent intervals allow values to be combined as averages and deviations. If the scale starts at zero, it becomes a ratio scale, which allows ratio statements such as "twice as big" or "half as much."

My suggestion is to implement a system already in common use throughout the world: the 100 -interval ratio scale, which is widely used for currencies and for grading performance and which is based on the most common counting practice, the decimal system.

The use of this scale to grade the quality of scientific measurements would not be new. Statistical confidence limits around a point estimate are expressed as percentages, as are the sensitivity, specificity and predictive values of diagnostic interventions. ${ }^{2,4}$ Probabilities and likelihoods may be expressed on the 100-interval scale or can be readily converted to it, while utility, the relative value of alternative choices, is also often expressed as a value out of $100 .{ }^{4}$ Perhaps most importantly, Bayes' factors, the mathematical expression of how disease indicants modify diagnostic hypotheses, fit well with the 100-interval scale and may also be used for therapeutic interventions. ${ }^{4-6}$ This scale even facilitates the use of odds, as odds to the base 100 are equivalent to percentages. ${ }^{6}$

The disadvantage of the system is that it may give a sense of precision that does not exist. For example, clinicians
THoffmann

Xenical

$2 \times 1 / 2$ page, $4 \mathrm{clr}$.

March 2, 2004 